\title{
Comparing strategies for improving thermal performance of an existing district heating (DH) network: low temperature DH in Omsk, Russia
}

\author{
Stanislav Chicherin ${ }^{1} *$ Lyazzat Junussova $^{2}$, Timur Junussov ${ }^{2}$ and Chingiz Junussov ${ }^{2}$ \\ ${ }^{1}$ Omsk State Transport University, Russia \\ ${ }^{2}$ Almaty University of Power Engineering and Telecommunications, Kazakhstan
}

\begin{abstract}
In Russia district heating (DH) systems are characterized by the high wear-out rate of key facilities, particularly energy distribution networks and plants, the inadequate reliability of operation, significant heat losses, and the polluting impact on the environment. The objective of this paper is to indicate the feasibility and advantage of the renovation on a traditional high-temperature DH network. All the calculations are performed in Zulu $\odot$, Russian commercial software for simulation of a district energy system's behavior. Reference operational data for the DH system was obtained from database established by the local heat supply company in the form of Microsoft Office Excel spreadsheet file. The second idea (Case-2) envisages installing a heat pump and increasing the supply temperature in peak load periods during the heating season to limit a size of a heat pump. Case- 3 and -4 are related to installing in-room terminal units and operating the system 'as is' respectively. Terminal units include consoles, fan-coils, blower coils, furnaces, chimneys, and radiant panels. The fifth option introduces low temperature district heating (LTDH) concept representing a paradigm shift in DH development and features a low supply temperature and smart control. When designing all errors should be less than local regulations allowable for each object. Presented research revealed that the issue of modernisation in Omsk, Russia cannot be easily and clear resolved. The future state-determination of results of DH network retrofitting is innovatively proposed in this paper.
\end{abstract}

\section{Introduction}

In Russia district heating (DH) systems are characterized by the high wear-out rate of key facilities, particularly energy distribution networks and plants, the inadequate reliability of operation, significant heat losses, and the polluting impact on the environment. The outdated DH systems require major rehabilitation in order to become competitive since the heating market fully opens up for competition in 1990s. System outworn have played an important role in driving the modernization of $\mathrm{DH}$ systems in Russia, where a national-level regulation empowers municipalities to fine local utilities for high levels of heat supply availability.

Kuprys \& Gatautis [1] inspected the implementation of rules for approval and apartment renovation (modernisation) project for cumulative contribution. As reported, key issues are the lack of transparency in the building modernisation process and the fact that district publicity cannot receive any tangible guaranties.

While in Russia DH systems constructed during the USSR era have achieved limits for the length of services, the rest of the world, especially the EU [2] and China [3] envisages the possibilities and advantages of $\mathrm{DH}$ technology.
There are plenty of energy production technologies and different types of energy demands at district scale. For instance, Sayegh et al. [4] considered a heat pump unit can be powered by energy generated in a mix of fuel sources, e.g. partially from conventional fossil fuels and renewable electricity. If renewable sources are used, a lower seasonal coefficient of performance gives more renewable heat to the system. Brange et al. [5] developed the idea for the consumer capable of generating energy for buildings in the neighbourhood once its own needs are met.

Vivian et al. [6] considered a low temperature $\mathrm{DH}$ system as we do and analysed covering peak loads which are rare in the systems where only space heating $(\mathrm{SH})$ is provided.

Thermal performance correlates with hydraulic characteristics such as resistance, pressure head etc. [7] Von Rhein et al. [8] highlighted novel thermo-hydraulic model for combined use and the optimization of the fifthgeneration of DH network. In Ref. [9] optimal pressure control (OPC) technique was compared with the traditional constant pressure difference control (CPDC) one.

Regarding the methods there is TRNSYS software, which was used to model options for a heat substation 
with a thermal power of $150 \mathrm{~kW}$ : without and with the use of a heat accumulator [10].

Among analytical methods the most popular ones are optimization [11] and real options valuation (ROV, ROA) $[12,13]$ also adapted here. The main objective of the study [14] is to analyze the feasibility of the auxiliary heat storage pipe system on an ordinary DH network and its operating performance.

The objective of this paper is to indicate the feasibility and advantage of the renovation on a traditional hightemperature DH network.

\section{Materials\&Methods}

Our model of a central plant should accept as input the supply temperature to the SH system and its heat load. The values of the operating parameters at the design condition are needed as well. The output from the model will be the supply and return temperatures. In order to reveal and reflect the influence of the outside temperature on reliability of heating networks, the outside temperature is changeable during the heating season, which is different from the previous research of heat distribution system with the hypothesis of constant outside temperature. We would like this model to be as accurate as possible while being in a simple form, thus avoiding numerical procedures involving it. However, it is not possible to obtain an accurate model if manual computations are used. All the calculations are therefore performed in Zulu@ , Russian commercial software for simulation of a district energy system's behavior.

To capture surplus expansion of the line pipe loops are designed (Case-1). To absorb the expansion of long runs of pipe, especially those in large dimensions an Ushaped routing is incorporated. Expansion loop and bend design is the responsibility of the designer, and is covered within this option. The expansion loop design is critical. Sufficient strength needs to be provided in the expans ion loop area to ensure that no pipe or insulation interference will occur due to supply temperature increase.

Another option is to use a heat pump for covering peak load or domestic hot water (DHW) supply (Case-2). Required temperature during peak load periods depends on the climate, availability of energy sources at higher temperature and total economy, and thus depends on the case considered. A typical supply temperature after a heat pump in Russia could be $45-55^{\circ} \mathrm{C}$.

Heat is hardly distributed, and more fuel is used to cover building's heating load until in-room terminal systems are not installed (Case-3). Surplus heat could be generated while loss to the ambient increases all the time and especially with high heat demand. If the heat delivered cannot satisfy the full heating load, insufficient part will be supplied from a local system which is used to supply heating energy to a single room or an entire apartment. The energy is also supported by electrical heaters in all the buildings. Case- 4 is related to operating the system 'as is'. With increasing frequency heating energy is supplied by a low-capacity boiler provided by the National Emergency Authority if it is not enough additional heat comes from privately owned electric heaters. Finally, the necessity of retrofitting to lowtemperature $\mathrm{DH}$ will be presented (Case-5). All the analysis is made by comparing DH network temperatures over to the ordinary heat supply methods from simulation results of study at 4 options. Although similar study options is used in literature (e.g. Im \& Liu [14] consider 6 scenarios, Kabalina et al. [15] do 8 cases, etc.), all of them have several limitations. Indeed, other authors process DH network temperatures too briefly not taking the variation of local and centralized services and the use of outworn components into account. In this paper, the supply and return temperatures are considered as variable quantities which depend on a DH system architecture and outdoor temperatures, moreover, actual ones of the latter are given.

\section{Case study}

Reference operational data for the DH system was obtained from database established by the local heat supply company situated in Omsk, Russia in the form of Microsoft Office Excel spreadsheet file. The city is in the centre of Siberia where design outdoor temperature is $37^{\circ} \mathrm{C}$. Shan et al. [16] chose the lowest point during the heating season of $-24.2^{\circ} \mathrm{C}$ as the design outdoor temperature. Weather data is provided by Omsk Committee of Weather Information. OCWI data files are weather files considered suitable for use with building energy simulation programs [17]. Temperatures were estimated as a daily average of temperature data between January and April, 2018 with the extreme outdoor temperature of -33.6 measured in Omsk city on 22/01/2018. Bjornebo et al. [18] suggest another approach. Since temperature data were only available for Boston in Massachusetts, which has a more moderate coastal climate compared to other parts of the state, data for Albany, NY were used to approximate the general extreme outdoor temperature of Massachusetts to avoid undersizing the DH systems. Whatever an approach is, climate affects both the end loads through prevailing construction practices and comfort requirements and the supply efficiency through network temperature and peak demand [19].

\section{Results\&Discussion}

\subsection{Maintaining a pipe network in normal conditions (Case-1)}

In this consideration main funds allocated for the $\mathrm{DH}$ system modernization are spent on pipelines repair. Distribution system is the most vulnerable element of DH system in Russia. The reasons are the poor quality of constructions of heat pipelines applied earlier, thermal insulation, valves, insufficient level of automatic control processes of transmission, distribution and malfunction at a substation. This is also due to increasing of moral and physical deterioration of pipelines and equipment due to continuous underfunding of works on modernization and reconstruction. 
Temperature changes cause dimensional changes in pipelines and equipment. For systems running at high temperatures, such as steam and hot water, the rate of expansion is high and significant movements can occur in short runs of piping. Even though rates of expansion may be low for systems operating in the range of lowtemperature water, they can cause large movements in long runs of piping, which are common in distribution systems. Fig. 1 was created by plotting the simulated operating points for the whole DH system; thanks to the software it is possible to be made at each possible actualto-design load ratio.

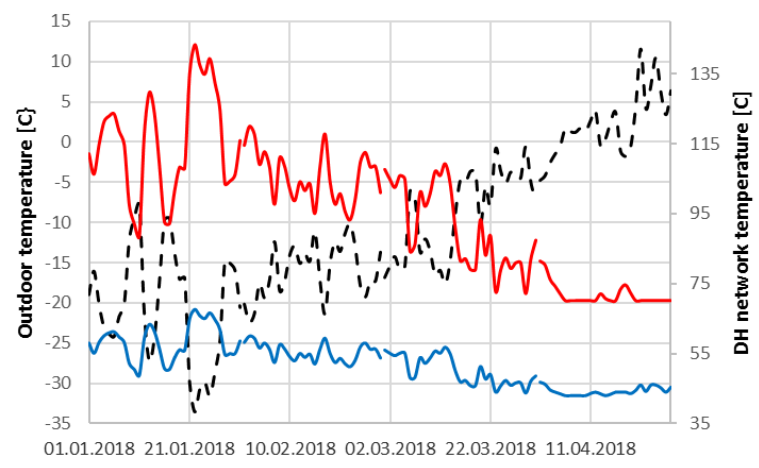

Fig. 1. The temperature profiles of the DH network.

The supply temperature can be varied between 88 and $143^{\circ} \mathrm{C}$ for outside temperature values between -8 and $34^{\circ} \mathrm{C}$ since the amount of heat obtained in the heat exchanger and the absolute plant generation capacity are enough to cover peak heating needs. In February, the highest supply temperature achieved is only $120^{\circ} \mathrm{C}$, while at the return side the corresponding value is not much lower than in January $\left(60\right.$ vs $\left.68^{\circ} \mathrm{C}\right)$. The above graphs indicate that system efficiency and operating points are highly dependent on the weather diversity and ability of distribution system to withstand high water temperature. In Ref. [16] the lower limit of the supply temperature for all consumers was set to $62^{\circ} \mathrm{C}$. Ayele et al. [20] show that all the supply temperatures are less than or equal to the maximum of the values specified at temp-supply hubs (e.g. $90^{\circ} \mathrm{C}$ at the hub 3). In Ref. [21], return temperature was set to be $30^{\circ} \mathrm{C}$ less than the supply temperature for all the substations. It can be seen that after building envelope modernization (in 2020, that includes the addition of solar thermal panels), installed solar collectors are able to generate more heat than required on an annual level.

\subsection{Retrofitting to a heat pump (Case-2)}

Being prosumer or just a low-scale generation reduces the primary fuel input by some $25 \%$ compared to a centralized production of the same amount of heat. However, the advantage if so, should be further quantified by the nature of the electricity input into a heat pump. One more time: if renewable sources are used, a lower seasonal coefficient of performance gives more renewable heat to the system [22].
The most significant seasons for energy saving, are spring and fall due to that most of the time ground heat can be used as a single source for the operating of a heat pump. And the lowest energy saving presents in January, the coldest period in Russia [23]. During that time, most of high-cost heat generated by a DH plant is supplied into their own buildings but not from a heat pump [24]. Only in April and March, once the thermal energy requirement becomes low, the self-generated heat from a heat pump can provide for almost all of the thermal demand. When the load is heating dominated (left half of the plots), the district flow rate is positive through the plant, meaning that the heat pump is active and no DH service is provided. For output after a heat pump, lower temperatures - up to $50^{\circ} \mathrm{C}$ - can be used. Then high temperature hot water is passed through a heat exchanger in each building to provide the, typically, $70-90^{\circ} \mathrm{C}$ water for distribution around the building and for heating DHW. Thus, the heated building receives lower bills than in case-1 because the SH supply water is just up-heated with that coming from the central plant, whose output temperature is dependent on the outdoor temperature.

\subsection{Installing in-room terminal units (Case-3)}

Terminal units include consoles, fan-coils, blower coils, furnaces, chimneys, and radiant panels. Terminal systems add heat energy or absorb the heat in the heated space served. The medium that transfers the heat from a heat source to the heated spaces may be the same as used with nonterminal systems. Typical uses of in-room terminal unit systems include old residential buildings, public and private kitchens, small shops, and terraced houses. The temperature profile of the primary side network after considering energy saving measures is shown as Fig. 2.

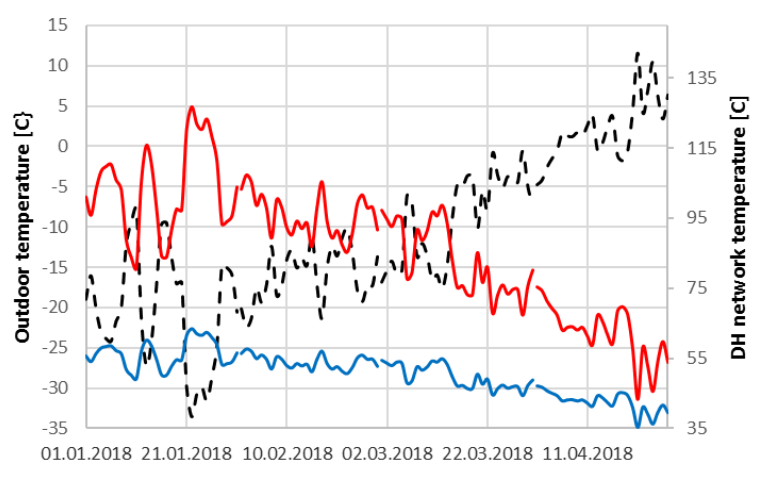

Fig. 2. Temperatures propagation. Water temperature at the outlets (top), at the inlets (bottom) and outside of the plant (black dashed).

From Fig. 2, it can be seen that the heat losses and transport delays are responsible for the harmful impact: the supply temperature at the periphery is lower and has huge delay compared to the consumer close to the producer.

As noted, the amount of supply temperature reduction and its variation according to the scenario is well synchronized with the weather, i.e. outdoor temperature. This is an observation which is less relevant to the return temperature, whose curve is much smoother (Fig. 2). 
Moreover the value of heat demand varies from 42 to $79 \%$ in January. In April, however, this range would change only from 10 to $35 \%$. Despite the surplus heat production being higher than that when only booster is on, at the minimal outdoor temperatures the recovered heat from the network and the absolute DH system capacity are still insufficient to cover the heating and DHW demands. The maximum instant supply temperature in winter can be up to $127^{\circ} \mathrm{C}$. In spring, summer and autumn, the supply temperature at the plant is around $65^{\circ} \mathrm{C}$ during half of the operating time. The lowest registered temperature values on the supply and return sides of a DH network here are 70 and $43^{\circ} \mathrm{C}$ (Fig. 2) while in Fig. 1 they are 69 and $45^{\circ} \mathrm{C}$, respectively.

\subsection{No refurbishment (Case-4)}

Extreme conditions hardly ever occur, but if they do, then the indoor temperature will go down leading to claims. These systems can operate with very low efficiency, since the only requirement is that a $\mathrm{SH}$ system remains hot. With working temperatures up to $40^{\circ} \mathrm{C}$, at city level, heat distribution system is pressurized every summer to avoid the possibility of failures.

As discussed above, an old building cannot operate with a maximum supply temperature of $115^{\circ} \mathrm{C}$ at the plant outlets during cold weather. They need water in a $\mathrm{SH}$ system at $95^{\circ} \mathrm{C}$ or slightly less, much warmer than $70-80^{\circ} \mathrm{C}$ after $115^{\circ} \mathrm{C}$-water is distributed to them once outdoor temperature achieves $-30^{\circ} \mathrm{C}$ or below. Water in a $\mathrm{SH}$ system at the temperature of $95^{\circ} \mathrm{C}$ can be done by preventing mixing cool return water at a substation, which makes a network unstable. Alternatively, and even with greater fuel efficiency, they can be supplied from a gas boiler or wood- or coal-burning stoves, both of which have a maximal environmental impact.

\subsection{Transferring to LTDH (Case-5)}

The locations of heat pumps (Case-2) or in-room terminal systems (Case-3) in the DH system should be determined from the designer's feasibility analysis and then entered in a local investment plan.

When designing all errors should be less than local regulations allowable for each object. High-temperature retrofitting (Case-1) will require supervision be provided in the each point at each stage of the DH system reconstruction for the purpose of control during system repair. This observation is similar to the considerations detailed as Case- 2 or -5 , except not all the equipment will be the same.

\section{Conclusions}

This study presents a framework to represent, aggregate, dynamic thermal model and modernize a $\mathrm{DH}$ system based on a high-level equation-based simulation software and a five-option feasibility study. Presented research revealed that the issue of modernisation in Omsk, Russia cannot be easily and clear resolved. However, the briefly and concise description meets the engineering need. The flexibility of the tool to take distributed generation into account makes it suitable to analyze the sensitivity of operation performance as a function of different renewable resources. The future state-determination of results of $\mathrm{DH}$ network retrofitting is innovatively proposed in this paper.

\section{References}

1. Kuprys, A. \& Gatautis, R. Comparison refurbishment models of district heating networks. J. Civ. Eng. Manag. 20, 11-20 (2014).

2. Delangle, A., Lambert, R. S. C., Shah, N., Acha, S. \& Markides, C. N. Modelling and optimising the marginal expansion of an existing district heating network. Energy 140, 209-223 (2017).

3. Hou, J. et al. Implementation of expansion planning in existing district energy system: A case study in China. Appl. Energy 211, 269-281 (2018).

4. Sayegh, M. A. et al. Heat pump placement, connection and operational modes in European district heating. Energy Build. 166, 122-144 (2018).

5. Brange, L., Englund, J. \& Lauenburg, P. Prosumers in district heating networks - A Swedish case study. Appl. Energy 164, 492-500 (2016).

6. Vivian, J. et al. Evaluating the cost of heat for end users in ultra low temperature district heating networks with booster heat pumps. Energy (2018). doi:10.1016/j.energy.2018.04.081

7. Badami, M., Fonti, A., Carpignano, A. \& Grosso, D. Design of district heating networks through an integrated thermo-fluid dynamics and reliability modelling approach. Energy 144, 826-838 (2018).

8. Von Rhein, J., Henze, G. P., Long, N., \& Fu, Y. (2019). Development of a topology analysis tool for fifth-generation district heating and cooling networks. Energy Conversion and Management, 196, 705-716. doi:10.1016/j.enconman.2019.05.066

9. Wang, H., Wang, H., Zhou, H. \& Zhu, T. Modeling and optimization for hydraulic performance design in multi-source district heating with fluctuating renewables. Energy Convers. Manag. 156, 113-129 (2018).

10. Turski, M., Nogaj, K., \& Sekret, R. (2019). The use of a PCM heat accumulator to improve the efficiency of the district heating substation. Energy, 187, 115885. doi:10.1016/j.energy.2019.115885

11. Chicherin, S., Junussova, L. \& Junussov, $\mathrm{T}$. Minimizing the supply temperature at the district heating plant - dynamic optimization. E3S Web Conf. 118, (2019).

12. Tunzi, M., Boukhanouf, R., Li, H., Svendsen, S. \& Ianakiev, A. Improving thermal performance of an existing UK district heat network: A case for temperature optimization. Energy Build. 158, 15761585 (2018).

13. Chicherin, S. V. Comparison of a district heating system operation based on actual data - Omsk city, 
Russia, case study. International Journal of Sustainable Energy, 2019, 38(6), 603-614. doi:10.1080/14786451.2018.1548466

14. Im, Y.-H. \& Liu, J. Feasibility study on the low temperature district heating and cooling system with bi-lateral heat trades model. Energy 153, 988-999 (2018)

15. Kabalina, N., Costa, M., Yang, W. \& Martin, A. Impact of a reduction in heating, cooling and electricity loads on the performance of a polygeneration district heating and cooling system based on waste gasification. Energy 151, 594-604 (2018).

16. Shan, X., Wang, P. \& Lu, W. The reliability and availability evaluation of repairable district heating networks under changeable external conditions. Appl. Energy 203, 686-695 (2017).

17. Chicherin, S. District Heating System Performance Charasteristics (Omsk, Russia, Nov. 2017). Mendeley Data, v1 (2017). doi:10.17632/4tgypy6hhf.1

18. Björnebo, L., Spatari, S. \& Gurian, P. L. A greenhouse gas abatement framework for investment in district heating. Appl. Energy 211, 1095-1105 (2018).

19. Chicherin, S., Volkova, A., \& Latõšov, E. GIS-based optimisation for district heating network planning. Energy Procedia, 2018, 149, 635-641
20. Ayele, G. T., Haurant, P., Laumert, B. \& Lacarrière, B. An extended energy hub approach for load flow analysis of highly coupled district energy networks: Illustration with electricity and heating. Appl. Energy 212, 850-867 (2018).

21. Cai, H., You, S., Wang, J., Bindner, H. W. \& Klyapovskiy, S. Technical assessment of electric heat boosters in low-temperature district heating based on combined heat and power analysis. Energy 150, 938-949 (2018).

22. Junussova, L. R., \& Chicherin, S. V. (2019). Improving a water treatment and a heating performance of the water-to-water heat pump: misallocation and available solutions. IOP Conference Series: Earth and Environmental Science, 288, 012092. doi:10.1088/1755-1315/288/1/012092

23. Junussova, L. R., Chicherin, S. V. (2019). Method of Aluminum Salts Extraction from Wastewater Using Desalination Technology: Syr Darya River Case Study. IOP Conference Series: Earth and Environmental Science, 288, 012008. doi:10.1088/1755-1315/288/1/012008

24. Zbaraz L.I., Chicherin S. V. Configuring a district heating plant under reconstruction: optimum quantity of boiler units. Bulletin of the Tomsk Polytechnic University. Geo Assets Engineering. 2019. V. 330. 7. 62-70 doi:10.18799/24131830/2019/7/2177. 